\title{
Hemato-Biochemical Studies on Egyptian Buffaloes and Calves Naturally Infected with Foot and Mouth Disease Virus Serotype SAT2
}

\author{
Essam A MAHMOUD ${ }^{1}$, Ahmed N F NEAMAT-ALLAH ${ }^{1 *}$ \\ ${ }^{1}$ Department of Clinical Pathology, Faculty of Veterinary Medicine, Zagazig University, Alzeraa Street \\ Postal Code 44511, Zagazig City, Sharkia Province, Egypt. \\ *corresponding author: drnemovete @yahoo.com
}

Bulletin UASVM Veterinary Medicine 73(2) / 2016,

Print ISSN 1843-5270; Electronic ISSN 1843-5378

DOI:10.15835/buasvmcn-vm: 11760

\begin{abstract}
Foot and mouth disease (FMD) is a highly contagious viral disease of all cloven footed domestic and wild animals. This work was planned to study the different markers for diagnosis of FMDV serotype SAT 2 in adult buffaloes and calves including clinical, hematological and biochemical examinations. Forty adult buffaloes 3 to 5 years old of age were divided into two groups of twenty buffaloes; the first group was obvious clinically healthy and the second was naturally infected with FMD virus (FMDV). In addition, twenty suckling calves 10 to 50 days old of age were divided into two groups of ten calves the clinically apparent healthy group and the naturally infected with the FMDV group. The recorded clinical signs were fever, salivation, loss of appetite, depression, lameness, vesicles, erosions and ulcers in the mucosa of the mouth, tongue, lips, gums, palate and between the claws in infected adult. Development of macrocytic normochromic anemia. Leucopenia, lymphopenia and monocytopenia were recorded in infected adult buffaloes and calves. Myocardial injury proved by presence of degenerated myocardial fibers and lymphocyte cell infiltration with a significant increase in cardiac markers as cardiac torponin I (cTnI), creatine phosphokinase (CPK) and lactate dehyrogenase (LDH) in addition to a significant hyperkalemia, hypocalcaemia and hypomagnesaemia in buffalo calves. Moreover, electrophoresis showed hyoproteinemia, hypoalbuminemia and hypoglobulinemia in the infected animals. It could be concluded that the elevation of cardiac markers emphasized that FMD is more severe in young calves than adult buffaloes. Therefore, it is recommended to evaluate the prognosis of FMD infection in calves by these markers.
\end{abstract}

Keywords: buffaloes, cardiac makers, Foot and Mouth Disease, hematology.

\section{INTRODUCTION}

Buffaloes are an important source for high quality animal proteins and represent an integral part of the economy in many developing countries worldwide. Nowadays, there is a great interest in buffalo breeding owing in part, because the recognized resistance of this species to a number of diseases (Ahmed, 2007). From the contagious diseases affecting livestock, FMD, which is known as aphtha's fever.

Foot and mouth disease (FMD) is a highly contagious disease of all cloven footed domestic and wild animals, caused by a picornavirus of the genus Aphthovirus (Barnett and Cox, 1999). FMD has a worldwide distribution and is endemic in Egypt. There is a major constraint to the international livestock trade because the severe economic consequences that FMD can generate because in infected animals, i.e., losses of meat and milk production (McCullough et al., 1986). FMD is characterized by the presence of some clinical signs in infected animals that include fever, blisters, vesicles, erosions and ulcers in the mucosa of the mouth, tongue, lips, gums, pharynx and palate. These le- 
sions were founded between the claws at the coronary band, and on the teats especially of the nursing animals. Lameness is evident in animals with foot lesions (Arzt et al., 2011; Musser, 2004).

FMD lead to high mortalities especially in young calves that die suddenly because of acute severe myocardial injury without developing the characteristic blister lesions, which noted in adult cattle's. The myocarditis of young animals is acute, with necrosis of muscle fibers and an intense infiltration of mainly lymphocytes (Alexandersen et al., 2003).

This work studies the different markers for diagnosis of FMD in adult buffaloes and buffalo calves including clinical, hematological and biochemical examinations.

\section{MATERIALS AND METHODS}

\section{Animals}

During an outbreak of FMD serotype SAT2 in 2012 at Sharkia Province, Egypt. Egyptian buffaloes (Bubalus bubalis) were examined. Diseased animals were diagnosed by official authorities of the Animal Health Laboratory at El-Doky, Cairo, Egypt. Serotyping of FMDV was done using the kits of solid phase competitive ELISA according to (Grazioli et al., 2012). Forty adult buffaloes of 3 to 5 years old were divided into two groups of twenty buffaloes; the first group was obvious clinically healthy and the second was naturally infected with FMD virus (FMDV). In addition, twenty suckling calves of 10 to 50 days old were divided into two groups of ten calves the clinically apparent healthy group and the naturally infected with the FMDV group. The routine clinical examination was carried out and the classical lesions of FMD were recorded. All animals were reared at farmers and fed properly as usual in these local areas.

\section{Blood sampling}

Two types of peripheral blood samples were collected from the jugular vein of the diseased and healthy animals. The first set of blood samples were collected in dipotassium salt of ethylene diamine tetra acetic acid (EDTA) tubes for hematological analysis, while the second set of blood samples were taken without anticoagulant in a sterile test tubes for separation of serum that was used to measure the biochemical parameters.

\section{Hematological studies}

The red blood cells count (RBCs), hemoglobin content $(\mathrm{Hb})$, packed cell volume (PCV), blood in- dices (MCV, $\mathrm{MCH}$ and $\mathrm{MCHC}$ ) and ifferential leucocytes counts were measured by an automatic cell counter (Hospitex Hemascreen 18, Florence).

\section{Biochemical studies}

Cardiac troponin I (cTnI) concentration was measured (Collinson et al., 2001), while serum level of calcium (Ca), phosphorous (P), potassium $(\mathrm{K})$, magnesium $(\mathrm{Mg})$, sodium $(\mathrm{Na})$, lactate dehyrogenase (LDH) and creatine phosphokinase (CK-MB) were measured in full automated biochemistry analyzer (chemray 240. USSR). Protein electrophoresis was quantitatively measured according to a method that was previously established (Laurell, 1966).

\section{Histopathological studies}

Small specimens were taken from heart, liver and spleen of freshly dead infected calves. The specimens were fixed in $10 \%$ buffered neutral formalin solution, dehydrated in gradual ethanol (70-100\%), cleared in xylene, and embedded in paraffin. Five-micron thickness paraffin sections were prepared and then routinely stained with hematoxylin and eosin (H\&E) dyes. The sections were mounted with Canada balsam and covered with cover slide to be ready for histopathological examination (Bancroft et al., 1996).

\section{Statistical analysis}

The data obtained from this investigation were statistically analyzed using student " $\mathrm{t}$ " test (Tamhane and Dunlop, 2000). Highly significant difference at $\mathrm{p} \leq 0.01$.

\section{RESULTS AND DISCUSSION}

The observed clinical signs were fever, salivation, loss of appetite, depression, lameness, blisters or vesicles, erosions and ulcers in the mucosa of the mouth, tongue, lips, gums, pharynx, palate and between the claws in adult (Figs.1$3)$. Mortality rate in young calves was $100 \%$. Necropsy of the freshly dead infected calved showed tiger heart appearance (Fig. 4) which in agreement with the previous studies (Arzt et al., 2011; Musser, 2004; Tunca et al., 2008) who mentioned the deaths in young's returned to severe acute myocardial injury without developing the characteristic blister lesions which noted in the adult. The severity of FMD in calves could be explained as FMDV can be replicated in mammary gland of the lactating buffaloes where the virus appears in the milk in higher titer (Sutmoller et al., 2003).These myocardial 
Tab. 1. Effect of FMDV serotype SAT 2 on cTnI, LDH and CK on adult buffaloes and calves (mean values \pm SE).

\begin{tabular}{ccccccc}
\hline \multirow{2}{*}{ Parameters } & \multicolumn{3}{c}{ Adult buffaloes } & \multicolumn{3}{c}{ Buffalo calves } \\
\cline { 2 - 7 } & Control & FMD & \% diff. & Control & FMD & $\%$ diff. \\
\hline cTnI (ng/ml) & $0.09 \pm 0.01$ & $0.12 \pm 0.01$ & 33.33 & $0.08 \pm 0.01$ & $1.78 \pm 0.02^{* *}$ & 2125 \\
\hline LDH (U/L) & $517 \pm 2.04$ & $567 \pm 7.82$ & 09.67 & $505 \pm 3.70$ & $733 \pm 27.41^{* *}$ & 45.14 \\
\hline CK-MB (U/L) & $265 \pm 9.67$ & $368 \pm 22.15$ & 38.86 & $176 \pm 2.04$ & $902 \pm 3.81^{* *}$ & 412.50 \\
\hline FMD & Foot and Mouth disease & cTnI & Cardiac troponin I & & & \\
LDH & Lactate dehydrogenase & CK-MB & Creatine phosphokinase & & &
\end{tabular}

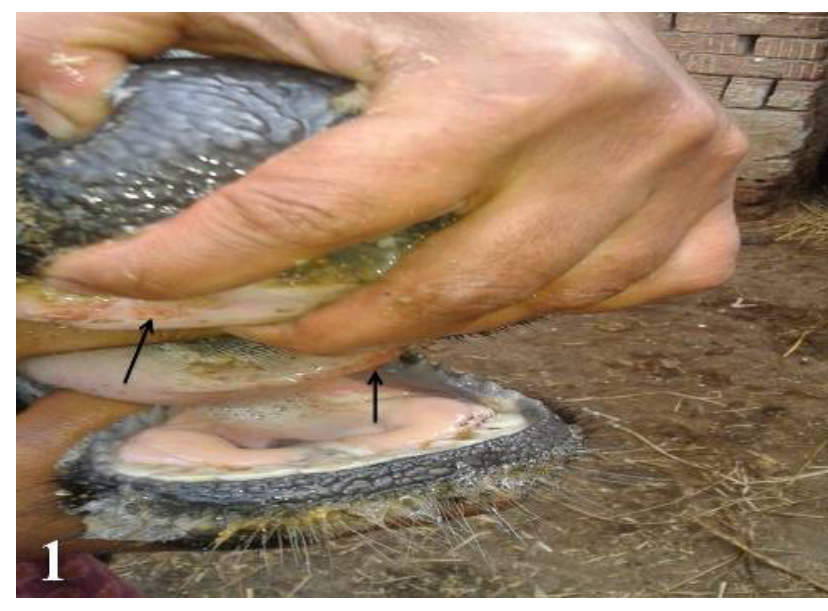

Fig. 1. Adult buffalo naturally infected with Foot and Mouth Disease Virus serotype SAT 2 showing ulceration on tongue and palate.

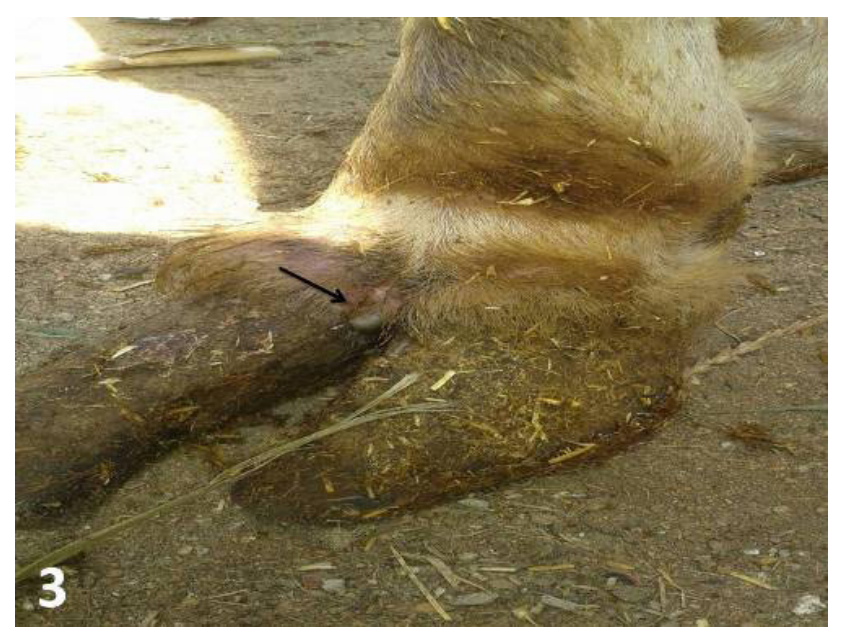

Fig. 3. Adult buffalo naturally infected with Foot and Mouth Disease Virus serotype SAT 2 showing ulceration between claws.

alterations proved by estimation of cTnI, LDH and CK (Tab. 1) that revealed a significant increase in the calves infected group compared with the

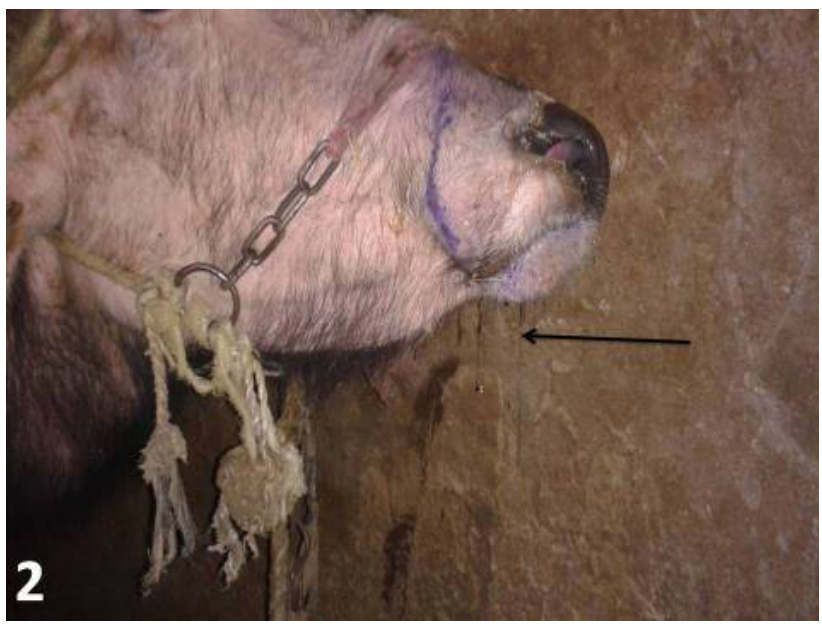

Fig. 2. Adult buffalo naturally infected with Foot and Mouth Disease Virus serotype SAT 2 showing ropy salivation.

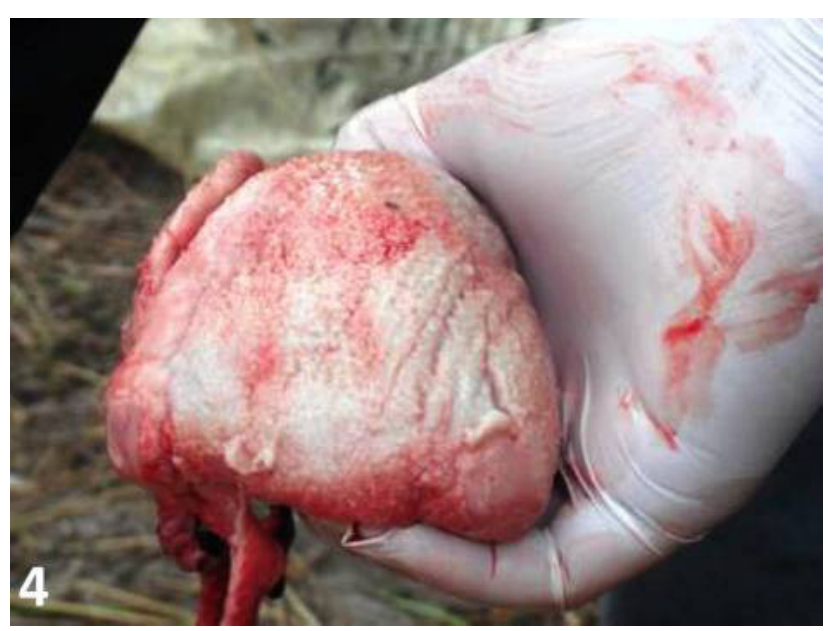

Fig.4. Freshly dead buffaloe calf naturally infected with Foot and Mouth Disease Virus serotype SAT 2 showing tiger heart appearance.

control calves and confirmed by histopathological studies of heart tissue which showed degenerated myocardial fibers and lymphocytic cell infiltration 


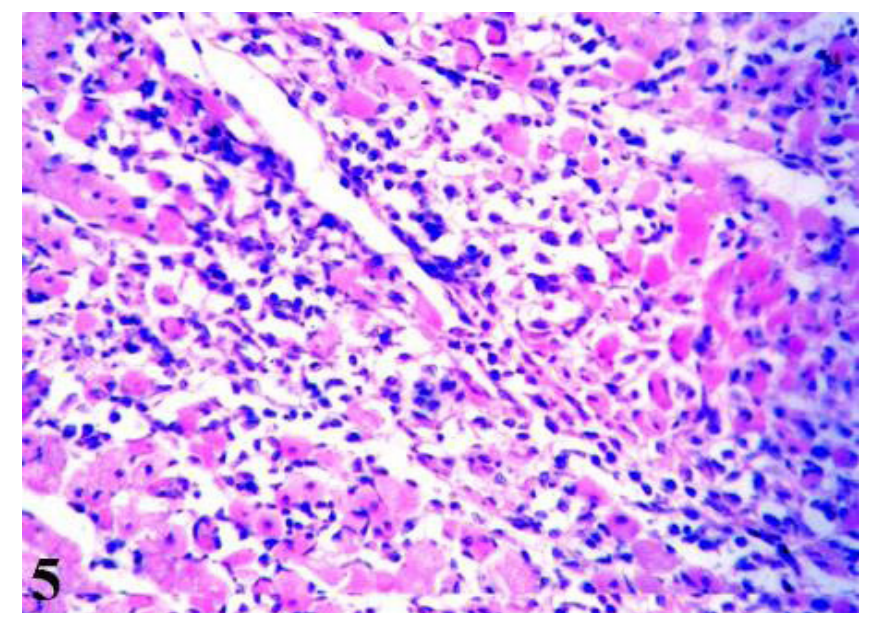

Fig. 5. Degenerated myocardial fibers and lymphocyte cell infiltration. $\mathrm{H}$ and $\mathrm{E}, \times 1200$.

Tab. 2. Effect of FMDV serotype SAT 2 on some hematological parameters on adult buffaloes and calves (mean values \pm SE).

\begin{tabular}{|c|c|c|c|c|c|c|c|}
\hline \multirow{2}{*}{\multicolumn{2}{|c|}{ Parameters }} & \multicolumn{3}{|c|}{ Adult buffaloes } & \multicolumn{3}{|c|}{ Buffalo calves } \\
\hline & & Control & FMD & $\%$ diff. & Control & FMD & $\%$ diff. \\
\hline & RCs $(\times 106 \mu \mathrm{l})$ & $8.33 \pm 0.27$ & $6.25 \pm 0.10^{* *}$ & -24.96 & $9.45 \pm 0.12$ & $8.32 \pm 0.28^{* *}$ & -11.95 \\
\hline & $\mathrm{Hb}(\mathrm{g} \%)$ & $13.56 \pm 0.23$ & $12.44 \pm 0.35^{*}$ & -08.25 & $13.74 \pm 0.05$ & $13.46 \pm 0.19$ & -02.03 \\
\hline & PCV (\%) & $40.70 \pm 0.36$ & $33.54 \pm 0.47^{* *}$ & -17.59 & $42.22 \pm 0.54$ & $39.12 \pm 0.44^{*}$ & -07.34 \\
\hline & $\mathrm{MCV}(\mathrm{Fl})$ & $48.85 \pm 0.57$ & $53.66 \pm 0.73^{* *}$ & 9.84 & $44.67 \pm 0.43$ & $47.01 \pm 0.61^{* *}$ & 9.71 \\
\hline & $\mathrm{MCH}(\mathrm{pg})$ & $16.27 \pm 0.14$ & $19.90 \pm 0.10^{* *}$ & 22.31 & $14.53 \pm 0.23$ & $16.17 \pm 0.19^{* *}$ & 11.28 \\
\hline & MCHC (\%) & $33.31 \pm 0.26$ & $37.09 \pm 0.31^{* *}$ & 11.34 & $32.54 \pm 0.32$ & $34.40 \pm 0.28^{*}$ & 5.71 \\
\hline & VBCs $(\times 103 \mu \mathrm{l})$ & $8.40 \pm 0.02$ & $5.60 \pm 0.27^{* *}$ & -33.33 & $8.18 \pm 0.19$ & $4.24 \pm 0.20^{* *}$ & -48.16 \\
\hline & LYM $(\times 103 \mu \mathrm{l})$ & $4.95 \pm 0.27$ & $2.23 \pm 0.36^{* *}$ & -54.94 & $5.47 \pm 0.05$ & $2.81 \pm 0.04^{* *}$ & -48.62 \\
\hline & $\operatorname{MID}(\times 103 \mu \mathrm{l})$ & $1.93 \pm 0.09$ & $0.66 \pm 0.04^{* *}$ & -65.80 & $1.41 \pm 0.11$ & $0.65 \pm 0.06^{* *}$ & -53.90 \\
\hline & $\mathrm{GRA}(\times 103 \mu \mathrm{l})$ & $1.53 \pm 0.18$ & $2.75 \pm 0.23^{* *}$ & 79.73 & $1.31 \pm 0.07$ & $0.77 \pm 0.08^{* *}$ & -41.22 \\
\hline \multicolumn{3}{|c|}{ FD Foot and Mouth disease } & \multicolumn{2}{|c|}{ MCV Mean corpuscular volume } & & & \\
\hline RBC & \multicolumn{2}{|c|}{ Red blood corpuscles } & \multicolumn{4}{|c|}{ MCH Mean corpuscular hemoglobin } & \\
\hline $\mathrm{Hb}$ & \multicolumn{2}{|c|}{ Hemoglobin } & \multicolumn{4}{|c|}{ MCHC Mean corpuscular hemoglobin concentration } & \\
\hline PCV & \multicolumn{2}{|c|}{ Packed cell volume } & \multicolumn{2}{|c|}{ WBC Total leucocytes count } & & & \\
\hline GRA & \multirow{2}{*}{\multicolumn{2}{|c|}{$\begin{array}{l}\text { Neutrophil, eosinophil and basophil } \\
\text { Monocytes and some eosinophil }\end{array}$}} & LYM Lymphocytes & & & & \\
\hline MID & & & & & & & \\
\hline
\end{tabular}

that confirms lymphocytic myocarditis (Fig. 5). So it is advisable to estimate the cardiac markers during an outbreak of FMD for calves; negative result must be isolated and fed milk from healthy buffaloes or even milk replacer.

Hematological studies (Tab. 2) revealed anemia in the FMD naturally infected animals either adult or calves when compared with the healthy animals. which may be a result of endocrinopathy which occurring secondary to FMD viral infection (Gokce et al., 2004; Radostits, 1994) or even may be attributed to that FMD causes a depression of erythropoiesis (Krupakaran et al., 2009). Development of macrocytic normochromic may be due to inadequate dietary intake of folic acid and vitamin B12, decreased absorption by damaged intestine and disturbed metabolism of liver .However, it is also possible that the mild anemia is associated with chronic disease with increased inflammatory cytokines (Ghanem and Abdel-Hamid, 2010). On the other side, when noticed the results of total and differential leucocytes count (Tab. 2), there 


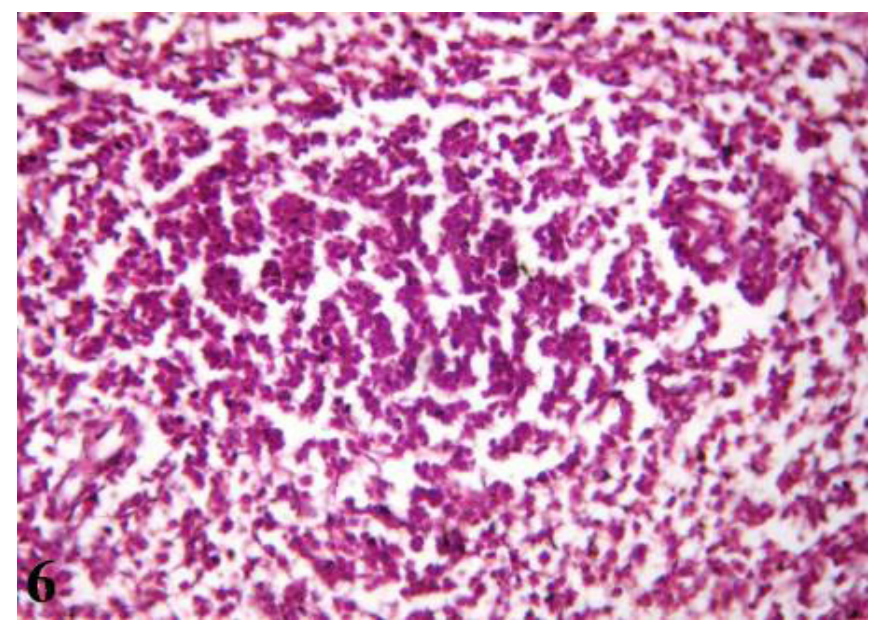

Fig. 6. Spleen of suckling calf showed depletion in white matter. $\mathrm{H}$ and $\mathrm{E}, \times 1200$.

Tab. 3. Effect of FMDV serotype SAT 2 on some serum electrolytes on adult buffaloes and calves (mean values $\pm \mathrm{SE}$ ).

\begin{tabular}{|c|c|c|c|c|c|c|c|}
\hline \multirow{2}{*}{\multicolumn{2}{|c|}{ Parameters }} & \multicolumn{3}{|c|}{ Adult buffaloes } & \multicolumn{3}{|c|}{ Buffalo calves } \\
\hline & & Control & FMD & $\%$ diff. & Control & FMD & $\%$ diff. \\
\hline & $\mathrm{Ca}(\mathrm{mg} / \mathrm{dl})$ & $10.20 \pm 0.13$ & $9.72 \pm 0.21$ N.S & -04.70 & $11.80 \pm 0.07$ & $7.40 \pm 0.05^{* *}$ & -37.28 \\
\hline & $\mathrm{P}(\mathrm{mg} / \mathrm{dl})$ & $5.52 \pm 0.26$ & $6.46 \pm 0.29 *$ & -19.20 & $7.92 \pm 0.41$ & $8.36 \pm 0.03$ N.S & 05.55 \\
\hline & $\mathrm{K}(\mathrm{mEq} / \mathrm{L})$ & $4.98 \pm 0.13$ & $6.58 \pm 0.13^{* *}$ & 32.12 & $7.44 \pm 0.17$ & $8.64 \pm 0.53^{* *}$ & 16.12 \\
\hline & $\mathrm{Mg}(\mathrm{mg} / \mathrm{dl})$ & $2.42 \pm 0.12$ & $1.18 \pm 0.10^{* *}$ & -51.23 & $2.14 \pm 0.41$ & $0.68 \pm 0.32^{* *}$ & -68.22 \\
\hline & $\mathrm{Na}(\mathrm{mEq} / \mathrm{L})$ & $139 \pm 0.49$ & $114 \pm 0.59^{* *}$ & -17.98 & $143 \pm 2.29$ & $100 \pm 1.10^{* *}$ & -30.06 \\
\hline $\begin{array}{l}\text { FMD } \\
\mathrm{Ca} \\
\text { P }\end{array}$ & $\begin{array}{l}\text { Foot and } \\
\text { calcium } \\
\text { phosphor }\end{array}$ & $\begin{array}{ll}\text { h disease } & \mathrm{K} \\
& \mathrm{Mg} \\
& \mathrm{Na}\end{array}$ & $\begin{array}{l}\text { potassium } \\
\text { magnesium } \\
\text { sodium }\end{array}$ & & & & \\
\hline
\end{tabular}

were marked leucopenia, lymphopenia and monocytopenia in infected adult buffaloes and calves which are in agreement with the findings of (Bautista et al., 2003; Díaz-San Segundo et al., 2006) which accompanied viral pathogenesis including systemic spread and viral shedding into environment to enable its transmission (Barya and Afzal, 1969). In addition to that leucopenia, lymphopenia and monocytopenia in infected animals may be due to the impaired function of residual T-cells with the transient immunosuppressive effect of FMD (Parida et al., 2006). This result confirmed with histopathological change in spleen that represented by depletion in white matter (Fig. 6). On the contrary, in the later stage of FMD infection, monocytosis were recorded by (Mohan et al., 2008) which might be related to prompt and quick recovery and healing of lesion in buffaloes. The difference may be due to long time intervals after infection while we examined the animals during the disease appeared on the animals but they examined the recovered animals. As monocytes are the precursor of macrophages, which play significant role in tissue remodeling and healing process (Benjamin, 1998).

Infected adult buffaloes showed a significant decrease in calcium, magnesium and sodium (Tab. 3 ) when compared with the normal animals. On the contrary, there were a significant increase in phosphorus and potassium in FMD animals as compared to the healthy control. This picture appeared more prominently in infected suckling calves. Our results are in accordance with that previously recorded (Krupakaran et al., 2009) who returned the increase in phosphorus to the higher ATP utilization and breakdown by the virus present in the body of the affected animals. The hypophosphatemia could be attributed to hypocalcaemia as their interaction where decrease in calcium leading to a reciprocal increase in phos- 
Tab. 4. Effect of FMDV serotype SAT 2 on proteinogram on adult buffaloes and calves (mean values $\pm \mathrm{SE})$

\begin{tabular}{ccccccc}
\hline \multirow{2}{*}{ Parameters } & \multicolumn{3}{c}{ Adult buffaloes } & \multicolumn{3}{c}{ Buffalo calves } \\
\cline { 2 - 6 } & Control & FMD & \% diff. & Control & FMD & \% diff. \\
\hline Total protein (g/dl) & $7.36 \pm 0.04$ & $5.54 \pm 0.04^{* *}$ & -24.72 & $8.08 \pm 0.07$ & $5.32 \pm 0.25^{* *}$ & -34.15 \\
\hline Albumin (g/dl) & $3.22 \pm 0.03$ & $2.78 \pm 0.04^{* *}$ & -13.66 & $3.28 \pm 0.07$ & $2.71 \pm 0.08^{* *}$ & -17.37 \\
\hline $\begin{array}{c}\text { Alpha1 globulin } \\
\text { (g/dl) }\end{array}$ & $0.16 \pm 0.01$ & $0.10 \pm 0.00^{* *}$ & -37.50 & $0.10 \pm 0.00$ & $0.10 \pm 0.00 \mathrm{~N} . \mathrm{S}$ & 00.00 \\
\hline $\begin{array}{c}\text { Alpha2 globulin } \\
\text { (g/dl) }\end{array}$ & $1.14 \pm 0.01$ & $0.90 \pm 0.04^{* *}$ & -21.05 & $0.88 \pm 0.02$ & $0.76 \pm 0.07^{* *}$ & -13.63 \\
\hline \begin{tabular}{c} 
Beta globulin (g/dl) \\
\hline $\begin{array}{c}\text { Gamma globulin } \\
\text { (g/dl) }\end{array}$
\end{tabular} & $0.94 \pm 0.03$ & $0.54 \pm 0.01^{* *}$ & -42.55 & $1.10 \pm 0.02$ & $0.66 \pm 0.05^{* *}$ & -40.00 \\
\hline
\end{tabular}

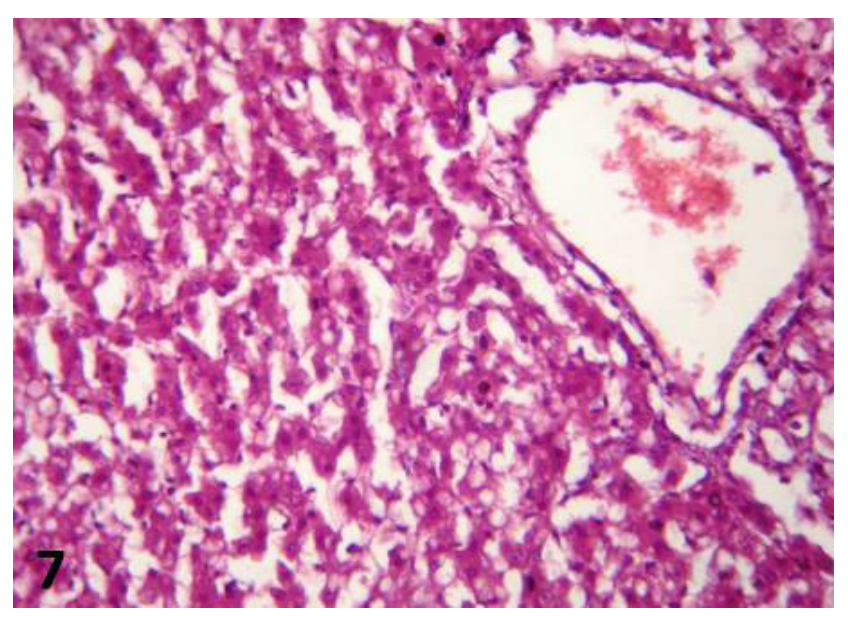

Fig.7.Liver of suckling calf showed fatty change in hepatic cells represented by empty vacuoles. $\mathrm{H}$ and $\mathrm{E}, \times 1200$.

phorus (Nahed, 2010). In turn, hypocalcaemia may be returned to the in-appetence, hypoproteinaemia and hypoalbuminaemia (Kaneko et al., 1997) (Gokce et al., 2004) resulting in decrease protein bounded calcium (Mousa and Galal, 2013). Our results revealed hyponatremia, hypomagnesaemia and hyperkalemia (Tab. 3) which similar to those results obtained by (Ghanem and Abdel-Hamid, 2010) On the same hand, this electrolyte profile could be achieved by hyper salivation which facilitates sodium loss. In addition, heat intolerance may aggravate the case.

Concerning the results of total protein and electrophoresis (Tab. 4), we found a significant decrease in total protein, albumin, alpha1globulin, alpha2globulin, beta globulin and gamma globulin in FMD adult buffaloes compared with the healthy control. The reported hypoproteinemia was attrib- uted to the hypoalbuminemia. From our opinion, the recorded hypoalbuminemia was due to starvation resulted from fever and erosions presented on the mouth and tongue of the infected animals. In addition to increased protein catabolism during infection and febrile conditions (Roussel et al., 1997). Moreover, hepatic damage, starvation, and enteropathy leading to protein loss (Gokce et al., 2004). Also, hypoproteinmia and hypoalbuminemia may be attributed to changes in pancreatic $\beta$-cell function which occurred during the clinical course of FMD as reported by (Gattani et al., 2011) Hypoglobulinemia either alpha globulins, beta globulins or gamma globulins tabulate the immunosuppressive effect of FMD (Mousa and Galal, 2013). Consistent with this result, (Nahed, 2010) explained the decrease in gamma globulin due to the inhibitory effects of some hormones like corti- 
sol that increased with FMD which in turn inhibits the antibody release before specific immunity achieved. Starvation (Ohama et al., 1994) of FMD infected calves explains presence of fatty change in hepatic cells represented by empty vacuoles in histopathology of liver (Fig.7).

\section{CONCLUSION}

It could be concluded that FMDV serotype SAT2 is more severe in the buffaloes calves than in the adult buffaloes which confirmed by an elevation of cardiac markers. Therefore, it is advisable to estimate these markers to help in the diagnosis and prognosis of FMD in calves. Calves showed negative result must be isolated and fed milk from healthy buffaloes or even milk replacer to avoid high mortality among them.

\section{ACKNOWLEDGMENTS}

The authors want to thank Prof. Dr. Abd ElMeneam A .Ali Professor and head of Pathology department .Faculty of Veterinary Medicine at Zagazig University for his help in examining and reading of the histopathological slides.

\section{REFERENCES}

1. Ahmed W (2007). Overview on some factors negatively affecting ovarian activity in large farm animals. Global Vet 1 (1): 53-66.

2. Alexandersen S, Zhang Z, Donaldson AI, Garland AM (2003). The pathogenesis and diagnosis of foot-andmouth disease. J Comp Path 129 (1): 1-36.

3. Arzt J, Juleff N, Zhang Z, Rodriguez L (2011). The pathogenesis of foot-and-mouth disease I: viral pathways in cattle. Transbound Emerg Dis. 58 (4):291-304.

4. Bancroft JP, Stevens A, Turner D (1996). Theory and Practice of Histopathological Techniques 4th ed. Churchill Livingstone, New York.

5. Barnett PV, Cox SJ (1999). The Role of Small Ruminants in the Epidemiology and Transmission of Foot-and-Mouth Disease. The Vet J 158 (1): 6-13.

6. Barya M, Afzal, H (1969). Persistence of Foot-and-Mouth disease virus in lymph nodes and blood of experimentally infected buffalo-calves in West Pakistan. Res Vet Sci 10: 321-325.

7. Bautista EM, Ferman GS, Golde WT (2003). Induction of lymphopenia and inhibition of $\mathrm{T}$ cell function during acute infection of swine with foot and mouth disease virus (FMDV). Vet Immunol Immunopathol 92 (1-2): 61-73.

8. Benjamin M (1998). Hematology. In Out line of Veterinary Clinical Pathology, 3rd ed. Kalyani publishers, New Delhi.

9. Collinson PO, Boa FG, Gaze DC )2001(. Measurement of cardiac troponins. Ann Clin Biochem 38:423-449.
10. Díaz-San Segundo F, Salguero FJ, de Avila A, Fernández de Marco MM, Sánchez-Martín MA, Sevilla N )2006(. Selective Lymphocyte Depletion during the Early Stage of the Immune Response to Foot-and-Mouth Disease Virus Infection in Swine. J Virology 80 (5): 2369-2379.

11. Gattani A, Gupta K, Koshal JG, Gupta RS (2011). Metabolic profile of foot and mouth disease stressed sheep in semi Arid region. J St Physio Bioch 7:148-153.

12. Ghanem MM, Abdel-Hamid OM (2010). Clinical, haematological and biochemical alterations in heat intolerance (panting) syndrome in Egyptian cattle following natural foot-and-mouth disease (FMD). Tropical Animal Health and Production 42: 1167-1173.

13. Gokce G, Gokce HI, Gunes V, Erdogan HM, Citil M) 2004). Alterations in some haematological and biochemical parameters in cattle suffering from foot-and-mouth disease. Turk J Vet Anim Scies 28:723-727.

14. Grazioli N, Ferris G, Spagnoli E, Brocchi E( 2012). Ready to use ELISA kit for FMDV diagnosis and serotyping tailored for Africa sess. Res. Gr. Tech. Committee of the Europ. Comm. Control FMD Terez, Spain, 29-31 Oct.

15. Kaneko JJ, Harvey JW, Bruss ML (1997). Clinical Biochemistry of Domestic Animals, 5th ed. Academic Press, California,USA.

16. Krupakaran R, Porcheziyan T, Sivseelan S (2009). Biochemical and hematological profile of foot-and-mouth disease affected crossbred cows in Karur District. Vet Pract 10 (1): 37-38.

17. Laurell CB 1966. Quantitative estimation of proteins by electrophoresis in agarose gel containing antibodies. Analyt Bioch 15: 45-52.

18. McCullough KC, Crowther JR, Butcher RN, Carpenter WC, Brocchi E, Capucci L, De Simone F (1986). Immune protection against foot-and-mouth disease virus studied using virus-neutralizing and non-neutralizing concentrations of monoclonal antibodies. Immunol. 58(3):421-428.

19. Mohan MS, Gajendragad MR, Gopalakrishna S, Singh N (2008). Comparative study of experimental Foot-andMouth Disease in cattle (Bos indicus) and buffaloes (Bubalis bubalus). Vet Res Commun 32 (6): 481-489.

20. Mousa SA, Galal MK (2013). Alteration in Clinical, Hemobiochemical and Oxidative Stress Parameters in Egyptian Cattle Infected with Foot and Mouth Disease (FMD). J Anim Sci Adv 3: 485-491.

21. Musser J (2004). A practitioner's primer on foot-andmouth disease. J Amer Vet Med Ass 224 (8): 1261-1268.

22. Nahed S (2010). Investigation of serum insulin and cortisol concentrations in foot and mouth diseaseinfectedcattle in relation to changes in serum biochemical variables and protein electrophoretic fractional profile. Global Vet 4 (5):450-455.

23. Ohama T, Matsuki N, Saito H, Tsukamoto K, Kinoshita M, Katsuragawa K, Okazaki S, Yamanaka M, Teramoto $\mathrm{T}$ (1994). Effect of starving and refeeding on lipid metabolism in suncus. . J Biochem 115 (2): 190-193.

24. Parida S, Oh Y, Reid SM, Cox SJ, Statham RJ, Mahapatra M, Anderson J, Barnett PV, Charleston B, Paton DJ (2006). 
Interferon- $\gamma$ production in vitro from whole blood of footand-mouth disease virus (FMDV) vaccinated and infected cattle after incubation with inactivated FMDV. Vaccine 24 (7):964-969.

25. Radostits 0 )1994(. Veterinary Medicine, 8th ed. W.B Saunders London.

26. Roussel AJ, Whitney MS, Cole DJ )1997(. Interpreting bovine serum chemistery profile. part1. Vet Med 92: 553-558.
27. Sutmoller P, Barteling SS, Olascoaga RC, Sumption KJ )2003(. Control and eradication of foot-and-mouth disease. Virus Res 91(1):101-144.

28. Tamhane A, Dunlop D )2000(. Statistic and data analysis from elementary to intermediate. Prentice Hall, Upper Saddle River, New Jersey.USA.

29. Tunca R, Sozmen M., Erdogan H, Citil M, Uzlu E, Ozen H, Gokce E )2008(. Determination of cardiac troponin I in the blood and heart of calves with foot-and-mouth disease. J Vet Diag Investi 20 (5): 598-605. 